\title{
Visión panorámica de la representación de objetos en la literatura hispánica reciente
}

\author{
Representation of Objects in Recent Hispanic Literature: A Panorama
}

Visão panorâmica da representação de objetos na literatura hispânica recente

\section{Vicente Luis Mora}

UNIVERSIDAD DE MÁLAGA, ESPAÑA

Profesor de la Universidad de Málaga. Doctor en Filosofía y Letras de la Universidad de Córdoba, España. Autor de La literatura egódica. El sujeto narrativo en el espejo en la literatura española contemporánea (Universidad de Valladolid, 2013) y $E l$ lectoespectador. Deslizamientos textovisuales entre literatura e imagen (Seix Barral, 2012). Ha publicado diversos artículos en revistas especializadas. Correo electrónico: vicenteluismora@yahoo.es 


\section{Resumen}

En la última literatura hispánica hay varias para posibilidades dirigidas a construir objetos ontológicos. En las actuales narrativa y poesía no es difícil establecer dos categorías de fundación ontológica: las cosas auráticas y las proyectadas, con diferentes significados y consecuencias, que serán discutidas en el texto.

Palabras clave: ontología; aura; hispánica; Busqued; Zambra

\section{Abstract}

In recent Hispanic Literature there are several ways of constructing ontological objects. In current poetry, and in narrative as well, it is not difficult to establish two categories of ontological foundation. These are, namely, auratic things and projected objects, with different meanings and consequences that will be discussed in the text.

Keywords: ontology; aura; hispanic; Busqued, Zambra

\section{Resumo}

Na última literatura hispânica têm várias possibilidades dirigidas a construir objetos ontológicos. $\mathrm{Na}$ atual narrativa e poesia não é difícil estabelecer duas categorias de fundamentação ontológica: as coisas auráticas e as projetadas, com diferentes significados e consequências, a serem discutidas no texto.

Palavras-chave: aura; hispânica; Busqued; Zambra

RECIBIDO: 9 DE OCTUBRE DE 2015. ACEPTADO: 22 DE OCTUBRE DE 2015. DISPONIBLE EN LÍNEA: 1 DE JULIO DE 2016

\section{Cómo citar este artículo:}

Mora, Vicente Luis. "Visión panorámica de la representación de objetos en la literatura hispánica reciente". Cuadernos de Literatura 20.40 (2016): 276-293. http://dx.doi.org/10.11144/Javeriana.cl20-40.vpro 
"Es entonces cuando averiguas que algunos objetos para ser vistos requieren de tu colaboración".

BELÉN GOPEGUI

"Les choses nous regardent".

PAUL VALÉRY

S OLEM OS LLAMAR COSA S los entes exteriores que llegan a nosotros o sobre los cuales no proyectamos una atención personalizada; en cambio, llamamos por costumbre objetos a los entes de la realidad exterior sobre los que, por algún motivo, hemos fijado de forma puntual nuestra atención- "cosas esperadas", los definía Valéry (66) - En consecuencia, y con cierta exageración, podríamos concluir que las cosas nos miran, mientras que miramos los objetos. En lo que sigue, trataremos de construir una panorámica general acerca de la representación de los objetos en la literatura hispánica reciente (entendiendo por hispánica la suma de hispanoamericana y peninsular), partiendo de esa doble perspectiva de observación, después de una consideración de entrada sobre la cultura de los objetos en la globalización.

\section{Objetos y globalización: los objetos nos hacen (socioeconómicamente)}

"Odiseo, al revelarle su identidad a su padre, Laertes, comenzó el inventario de su herencia con trece perales y diez manzanos".

GUY DAVENPORT

A lo largo de este texto vamos a partir de una obviedad: hay una relación ínsita y estrecha entre los sujetos y los objetos, pero podemos partir de una base clara: los objetos, el dominio de las cosas, no solo nos permite relacionarnos a veces en sociedad, sino que también es una muestra de estatus y de pertenencia a un sector o clase concretos de la sociedad actual. Y ello es así, antropológicamente, desde el comienzo de la historia registrada. Como explica Almudena Hernando: [...] posiciones más recientes comienzan a demostrar la imposibilidad de separar sujetos y objetos en el análisis de una cultura: si los objetos de distintas culturas son diferentes es porque las personas que los fabrican también lo son. Desde ese punto de vista, resulta obvio que las personas construyen la cultura material tanto como la cultura material construye a las personas. Es 
decir, somos como somos porque utilizamos determinados objetos, y porque somos así, fabricamos unos objetos y no otros. (19)

Incluso la forma de mirar los objetos, como escribiera Benito Pérez Galdós, tiene su importancia: "A las personas educadas entre una sociedad escogida se las conoce por el modo de andar y por el modo de contemplar los objetos" (133). Siguiendo este parámetro de actuación y teniendo en cuenta que la nuestra es una sociedad globalizada, donde vivimos rodeados de unos 20.000 o 25.000 objetos cotidianos (Norman 26), el aserto de Hernando debería implicar una relación entre esta sociedad y el dominio (económico, cultural, etc.) de algunos objetos concretos. Como explicó José Luis Brea, "en la forma universalizada de mercancía que determina el estatuto del objeto en la organización sistémica de lo social propia de las economías postindustriales [...] las cargas de significancia asociadas a su supuesta rala materialidad por la semiotización de los mundos-devida determinan su condición alegórica" (55). Y, en realidad, es de este modo: si tenemos en cuenta, por ejemplo, que en América Latina la clase media ha aumentado un 50\% en solo seis años, al pasar de 103 millones de personas a 152 según el Banco Mundial y a 275 millones según la Organización para la Cooperación y el Desarrollo Económicos, como recuerda Frédéric Martel, no debe extrañarnos que el propio Martel apunte a continuación que la alegorización de ese ascenso se logra a partir de un objeto concreto, de una cosa: "ahora pertenecer a la clase media también pasa por dos nuevos símbolos: el acceso a Internet y la posesión de un móvil. He aquí por qué el Smartphone, que combina ambas cosas, se está convirtiendo en el emblema de la emergencia de América Latina" (79). De lo que se deduce que si el teléfono móvil inteligente y conectado puebla el imaginario latinoamericano, pronto poblará asimismo las ficciones americanas en español, como sucedió con las peninsulares a finales de los años noventa y principios del presente siglo (Mora, La luz 201-209).

La cuestión es que, como ha apuntado Ernesto L. Francalanci, "la irrupción a partir de la revolución industrial de nuevas categorías de observación, como por ejemplo, y en primer lugar, la del objeto en tanto producto y mercancía, lleva a la filosofía a tratar con la realidad de la praxis y sus implicaciones con la política y la economía" (15), creando lo que él denomina estética difusa a la hora de analizar filosóficamente las creaciones artísticas. Sin seguir exactamente esta perspectiva, pero admitiendo su reivindicación de un modelo más comprensivo que los habituales, examinamos más adelante varias manifestaciones -literarias, en nuestro caso - de la identificación objeto-sujeto y ahondaremos en ella. Como 
meros ejemplos introductores, citamos que la mujer protagonista de "La novia", de Chéjov, comprende la vulgaridad de la vida que le espera al ver los objetos de su futura casa (272-273) y que Andrés Ibáñez retrata en Brilla, mar del Edén (2014) a un rabino por el contenido de su maleta abierta y las cosas caídas sobre el protagonista (16-18). Pero antes de comenzar el tratamiento de las concretas manifestaciones de las cosas en la literatura hispánica actual, convendría hacer un aparte metodológico para saber de qué hablamos cuando hablamos de una cosa.

\section{Ontología científica}

Hay que destacar en los últimos años la aparición de una generación de poetas y narradores que, gracias una perspectiva científica (en ocasiones realmente científica, pues algunos de ellos son físicos o matemáticos de formación), tiene una forma distinta de mirar las cosas y de expresarlas, bajo una perspectiva que podemos llamar subatómica. Los objetos se observan como racimos de átomos y los cuerpos se ven como cadenas moleculares, que suman esencia por agregación compleja, donde el sentido viene provisto por el ADN y la evolución biológica. Desde esa perspectiva podemos leer, por ejemplo, al poeta Eduardo Moga decir: "Cuando estoy solo, / las cosas, solas, se engríen, / se desquician por ser lo que son, / enloquecen de moléculas y topónimos, / y hurgan en el fondo de los ojos con sus extremidades de humo, / y reparten su muerte como agua / encallecida" (29), una visión que roza el nominalismo de Sartre (138). Y ahora, la visión cientifista y literaria a la vez del poeta y narrador Agustín Fernández Mallo, físico nuclear de formación:

Pero, aparte, los objetos son unas cosas rarísimas: si los acercamos mucho a nuestro campo de visión, por ejemplo con un microscopio, se convierten en estructuras simples, totalmente organizadas y con una geometría matemáticamente tratable. Después, si nos alejamos lo suficiente, entramos en el orden de magnitud del día a día, donde tales objetos se solapan y mezclan para conformar un paisaje de geometría compleja y cotidiana, impura y difícilmente analizable, de la que solo las teorías del caos y otras afines consiguen dar buena cuenta: es la escala humana. Y si nos alejamos más, como puede ser el caso de la visión de la tierra desde un avión, volvemos a verlo todo asombrosamente simple y organizado, con una geometría muy parecida a aquella vista al microscopio. (173)

Obsérvese cómo esta última mirada aprehende tres escalas distintas de observación compleja de las cosas y puede tender redes de familiaridad entre ellas, englobándolas bajo la misma operación discursiva. Es poco probable que 
existan muchos escritores capaces de tener esta mirada triple; por lo común el prisma se agota, como en el Michel Houellebecq de Las partículas elementales (1998), en la comparación entre la observación a simple vista y la microscópica y subatómica, sin llegar a establecer parangones entre los estados ordenados de la materia. Otro ejemplo sería el matemático, narrador y poeta español Javier Moreno. La conclusión última a la que se llega mediante esta visión científica es a la disolución de las fronteras entre sujetos y objetos, o entre cosas y personas, volviendo un poco a la visión presocrática, por cuanto al final todo resulta estar compuesto de lo mismo. Bajo una mirada científica, el mundo es un continuo de partículas agregadas de diferentes formas, pero que tienen esa condición de partículas como común denominador - otro ejemplo en la argentina Gabriela Cabezón Cámara (46), donde el materialismo parece unificar a los cuerpos; mientras que la creencia o el espíritu los distinguen, en un retorno dualista-. De ahí que, como queda claro en este fragmento del escritor argentino Ezio Maqueira, la desaparición del yo tiene lugar con la desintegración corpuscular del cuerpo:

Había leído en el diccionario que "descomposición" significaba "separación de las partes". Ahora, mientras con cada gusano se le iba una partícula del cuerpo, presenciaba - entre maravillado y temeroso- su propio proceso de separación. Era como si lo estuvieran demoliendo: cada una de las células que durante ochenta y dos años había confluido en ese mismo espacio para darle forma a don Arturo, ahora se desprendía de él. [...] era capaz de imaginarse el susurro de cada gusano llevándose una porción minúscula de su cuerpo. Era probable que ya estuvieran en el cerebro. Mientras pensaba, alguno estaría acercándose a esa última neurona donde se había refugiado su conciencia. (116-117)

Como se desprende de este texto de Maqueira, la mayoría de estas visiones corpusculares pertenecen, en principio, a un modo materialista de entender la existencia, aliviado de cualquier trascendencia por su prurito científico.

\section{Cosas auráticas y cosas proyectadas}

Entrando ya en cuestiones puramente literarias, la ontología objetual nace de una primera dialogía de la que surge el hilo conductor de este texto: la distinción entre las cosas que actúan en nosotros y aquellas sobre las que proyectamos la luz simbólica. Las primeras nos miran, a las segundas las miramos.

Respecto a las primeras, podríamos denominarlas auráticas. Partiendo de Walter Benjamin, dice Didi-Huberman: "aurático sería el objeto cuya aparición despliega, más allá de su propia visibilidad, lo que debemos denominar 
sus imágenes [...] que se nos imponen como otras tantas figuras asociadas que surgen, se acercan y se alejan para poetizar, labrar, abrir tanto su aspecto como su significación, para hacer de él una obra de lo inconsciente" (95). Al tratar, en el mismo lugar, acerca de los objetos oníricos, cita Didi-Huberman a Paul Valéry: "Pero, en el sueño, hay una ecuación. Las cosas que veo me ven tanto como yo las veo" (95). Es decir, las cosas auráticas generan una relación de doble vuelta entre observante y observado, de forma que el observante resulta ser el objeto que inspira en el observado (el escritor) la reacción de la escritura. Un objeto aurático por excelencia es el espejo, al que no nos referiremos por haber tratado sobre este en La literatura egódica (2013), pero en rigor cualquier objeto puede volverse aurático por el tratamiento literario que reciba. Así, cosas auráticas serían las citadas en "Las cosas" por Ángel Crespo:

Todas las cosas tienen

ojos para mirarnos,

lengua para decirnos,

dientes para mordernos.

Vamos andando igual que si nadie nos viese,

pero las cosas nos están mirando. (23)

Uno de los ejemplos clásicos más extremos de objeto aurático es el de la jarra que da pie al poema de Wallace Stevens "The Anecdote of the Jar" (120), y que estudiamos ampliamente en Pasadizos (2008), al vincularlo con otros objetos o espacios auráticos de Leopardi o Petrarca. Así, los objetos auráticos desordenan nuestra experiencia del conocimiento de las cosas, pues actúan sobre nuestra percepción, como el caso de un relato de González Sainz, donde un maniquí femenino trastorna la percepción de un viandante obsesionado con él mismo (88-89). En resumen, lo importante es retener que el hecho de que algo nos mire es turbador pues, como dice Daniel C. Dennett, la mirada ajena puesta sobre nosotros es instintivamente considerada un gesto de conciencia, como una prueba de que hay alguien y no solo algo. Así, podríamos citar la que Daniel Dennett definió como "experiencia extrañamente inquietante" (27-28), que consistía en compartir la misma habitación que un robot llamado Cog, programado para mirar a los ojos a las personas de su entorno próximo.

Frente a esta condición aurática, propongo que los objetos simples o cosas proyectadas son aquellos sobre los que el discurso literario (o filosófico, como en los casos de la navaja de Ockham o las rosas de Locke) fija su atención expresa, abdicando de su condición de cosa, con una de estas cuatro finalidades: 
A. Para arrogarles características que a primera vista no están presentes en ellos, sea mediante la personificación o la animalización: "Las cosas tienen un ser vital: las cosas / tienen raros aspectos, miradas misteriosas", escribió Rubén Darío en su "Coloquio de los centauros" (432). Para el prosista Eloy Tizón, "Todos los objetos del cuarto, incluidas las esquinas de la mesa y las patas de las sillas, me miran comprendiendo que estoy en un lío. Hay que saber lo que es sentirse comprendido por un grifo o una persiana" (57).

в. Para destacar alguna de sus características y volverla reveladora a los efectos de la trama narrativa o del discurso poético, convirtiendo las cosas en sucesos. Ejemplo de uso proyectado revelador son las largas descripciones de objetos presentes en Papá Goriot (1835) de Balzac, de innumerable detallismo. El descriptivismo balzaquiano sirve a su propósito realista, pero también a la finalidad conductista de explicar el mundo socioeconómico, familiar y cotidiano de las personas según las cosas de que se rodean. Luego ahondaremos en esto a partir de una novela del argentino Carlos Busqued.

c. Para otorgarles valores simbólicos, o convertirlas en cosas mitificadas, según la opinión de Gadamer (22) a partir de Rilke; como decía Mario Levrero, "hay objetos exteriores que simbolizan objetos o procesos interiores" (citado en Gandolfo 41).

En otros supuestos las cosas aparecen simplemente expuestas con fines anticlimáticos, como cuando Flaubert opone la conmoción interna de Emma Bovary a la calma de las cosas, en una mirada oposicional (no en vano dice Zizek que el objeto es lo que objeta [25]).

\section{Los objetos poéticos y el topos de las cosas tras la muerte}

"Mientras dura la lectura del poema [...] oímos que las cosas hablan [...] o si se quiere, que las cosas nos miran con nuestros propios ojos".

JAIME GARCÍA MAFFLA

Como iremos demostrando, la literatura contemporánea, y muy especialmente la poesía, podrían constituir una ontología de los objetos poéticos bastante madura, fruto en parte de su mirada científica y en parte de su insistencia. En efecto, la poesía contemporánea en español, como seguramente sus antecesoras en el tiempo, tiene una auténtica obsesión por las cosas, en cualquiera de las manifestaciones fenomenológicas que ya hemos visto. Cabe preguntarse el porqué de esta proliferación. Según la filósofa María Zambrano, "La poesía ha estado siempre abierta a las cosas, arrojada entre ellas, arrojada hasta la perdición, hasta el olvido del sí, del poeta. Mas por este olvido de sí, más próxima siempre a estar abierta 
a ese último fondo o raíz de la existencia" (114). En realidad, si nos detenemos a pensarlo, no faltarían numerosos ejemplos donde hay unidad entre la existencia de las cosas y nuestra propia existencia, como en el topos de los objetos que restan tras la muerte. Pero no solo eso; la poesía trenza un vínculo entre el observador y las cosas observadas, que a veces acuden como testimonio de existencia contempladora y, a veces, como estamos viendo, devuelven la mirada al poeta o a la voz elocutoria que sostiene el poema.

Los ejemplos de poesía reciente sobre las cosas en castellano son incontables; por destacar algunos tratamientos, recordemos algunos versos de "Efectos personales", del costarricense Alfredo Trejos:

Te estuviste metiendo de nuevo con mis cosas.

Este es mi disco

de John Coltrane

y sé que estas son tus huellas. [...]

Pero no podés ir por ahí

marcando mis cosas, derritiendo mis días. (36-37, cursivas del original)

Y este poema de la cubana Sheyla Valladares:

Volver a aprender los objetos

por la forma que tienen cuando los tocamos,

la piel y la temperatura / que estrenan,

cada vez que con los ojos cerrados

comenzamos, otra vez, a reconocerlos.

No se siente igual mi conejo de peluche

que la superficie de las teclas del piano,

la piel arrugada de la naranja,

que la madera del sillón,

pulida por el tiempo

y las manos de mi abuela.

En la poesía - quizá más claramente que en la narrativa - se aprecia una especial capacidad de empatizar con las cosas y de verter una mirada precisa y distinta sobre los objetos cotidianos - una especie de desfamiliarización, sobre la que luego volveremos-, de forma que el lector percibe dimensiones desconocidas en los objetos de su entorno. Un ejemplo canónico sería el poema de Wyslawa Szymborska, cuando toma algo tan simple como la cebolla y la analiza casi metafísicamente: "No tiene entrañas la cebolla./ Es cebolla cebolla de verdad, 
/ hasta el colmo de la cebollosidad. // Ser no contradictorio la cebolla, / logrado ente la cebolla. / Es una, simplemente otra, / la mayor una menor contiene / y la siguiente a la siguiente, / y así la tercera y la cuarta" (134). Esta cebollosidad, que trae a la mente la "naturaleza cristalina" de la "Oda a la cebolla" de Pablo Neruda (614), opera el milagro que Eagleton veía imposible para la filosofía, cuando dice que se puede hablar de cocodrilos pero "nadie se ha topado jamás con la "cocodrilidad"' (11), como categoría abstractiva. La visión poética de los objetos permite ese y otros milagros de observación, subversiones totales que vienen de miradas de soslayo. Precisamente "De soslayo" se titula un poema de Virginia Aguilar Bautista, que reza de este modo: "Aunque me haga la loca / desde hace tiempo sé / que mi ventilador pasa las páginas / sin leerlas; por eso, / aunque no me lo pida, / le explico los finales" (6o). Habría muchísimos ejemplos de esta mirada sorprendentemente afinada en su percepción diferente de cosas y entornos próximos, de los que escogemos otros dos: "Me está grande el jersey. / Me están pequeños los zapatos. // Ni yo soy de mi talla" (Aguado 52); "La ceguera del pájaro al entrar en la habitación y chocar contra la estricta geometría de paredes y techos" (Santana 10).

El resultado de esta forma de mirar es que se recupera la capacidad de fundación ontológica de los objetos; de pronto aquella declaración de Emilio Lledó, por la cual "no vemos ni sentimos objetos filosóficos en nuestra circunscrita experiencia de cada día" (76) es de súbito puntualizable, por cuanto la poesía nos permite visualizar (y, con ello, experimentar) toda clase de objetos, incluso los imaginarios o imposibles, que aparecen de pronto brutalmente ante nosotros gracias al poder de la imagen poética. Un tema muy recurrente es el de la sobrevivencia de los objetos tras nuestra muerte, que implica una perduración ontológica del ser de las cosas más allá de nuestro ser. Junto al conocido poema "El viaje definitivo" (36) de Juan Ramón Jiménez, podríamos agregar estos ejemplos hispanoamericanos:

De los Campos Elíseos o al dar vuelta

la extraña callejuela de la Luna,

mi defunción se va, parte mi cuna,

$\mathrm{y}$, rodeada de gente, sola, suelta,

mi semejanza humana dase vuelta

y despacha sus sombras una a una.

Y me alejo de todo, porque todo

se queda para hacer la coartada.

(César Vallejo 94) 
[...] ¡Cuántas cosas,

limas, umbrales, atlas, copas, clavos,

Nos sirven como tácitos esclavos,

Ciegas y extrañamente sigilosas!

Durarán más allá de nuestro olvido;

No sabrán nunca que nos hemos ido.

(Jorge Luis Borges 370)

El peine, las horquillas, las fíbulas de marfil

en el armario.

Oh tristeza dulcísima.

(Jeanette L. Clariond 77)

Toda la pena de las cosas:

su estante soledad,

rala gramática del tiempo

esparce la maleza del desuso

sobre estratos de sombra.

Reja de hierro,

piel de polvo,

estragos de óxido en un clavo

emergido en el flujo del desorden;

giro pésimo

de una puerta que fue árbol:

se forman con muerte las cosas,

se hacen cosas de morir.

Después huyen hacia sí de la memoria.

(Edgardo Dobry 49)

\section{Los objetos en la narrativa: Zambra o la cosificación del elemento}

Dentro de la narrativa, también podemos observar similares tratamientos a los establecidos de modo general. Así, la personificación o la animalización de las cosas es una característica habitual en la literatura fantástica, desde sus inicios míticos grecolatinos. Las cualidades de transformación admiten muchas variantes, desde la ovidiana clásica hasta el método paranoico-crítico de Dalí, que favorece el deslizamiento por el cual "una cosa acaba convirtiéndose en otra" (Ramírez 25). En el caso de los objetos proyectados simbólicos o mitificados, los narradores 
son tan conscientes como los poetas de las posibilidades de reverberación, y las utilizan de forma constante, como el argentino Bruno Galindo (38). Respecto a la proyección reveladora de los objetos, es frecuente como modo de reflejar afectos, cualidades, circunstancias o defectos de los personajes: "Su infancia recuperada a través no de recuerdos personales sino de objetos y lugares personales que se recuerdan, de reinventadas partes reales" (Fresán 366).

Un asunto que también suele abordarse es el de las cosas abordadas o derrelictas, que en narrativa suele relacionarse con el tema de la escasez, por lo cual el tratamiento literario es más canónico el de Robinson Crusoe (1719), de Daniel Defoe. En algunos casos se afronta desde la perspectiva de la crítica social al consumismo excesivo; en cambio, en novelas como Plop (2003), Frío (2011) y Subte (2011), del argentino Rafael Pinedo, la acumulación de objetos no tiene un sentido consumista, sino de pura supervivencia: cada artefacto, resto, cosa o escombro tiene un alto valor en la narración precisamente por el régimen de privación y escasez de los protagonistas.

Pero la narrativa tiene diversos modos de acercarse a los objetos. En su reciente y valeroso libro Facsímil (2015), el chileno Alejandro Zambra lleva a cabo una tarea que suele ser más propia de un poeta que de un narrador, una operación de detención observadora mediante la cual la obra llama la atención sobre aquello de que está compuesta, sobre su ser más íntimo: la palabra. Mientras que es habitual que la poesía rompa su discurso para fijarse en las propiedades de una palabra, como puede verse en los nominalismos de Juan Ramón o Mallarmé, en la prosa no es tan frecuente; sin embargo, Zambra, que en Mis documentos ya había escrito "le molestan esos nombres tan cargados, tan plenos, tan directamente simbólicos: Paz, Consuelo. Piensa que si alguna vez llega a tener un hijo va a inventar un nombre que no signifique nada" (183), va más allá y, repescando los antiguos exámenes para el acceso a la universidad chilena, pregunta al lectorestudiante cuál es la palabra de la serie que desentona, que no pertenece al hilo lógico o al campo semántico de la planteada. Confiar el desafío al lector tiene la consecuencia de que este debe replantearse sus propios marcos lingüísticos, así como su conocimiento léxico y - como lógico corolario, previsto inteligentemente por Zambra - su propio marco estético, su concepto de literatura, aquí enteramente devastado para regresar a su origen cabal, atómico - la palabra - con la intención de, a partir de ahí, ser reconstruido de nuevo por completo, reintegrándose dentro de un discurso mayor o metadiscurso que cuestiona hábilmente el modo en que los propios discursos formalizan el poder. En especial, se persigue en Facsímil el hecho de visualizar el modo en que los modelos educativos cosifican o reifican al individuo al sustituir la evaluación de los conocimientos por el cómputo 
matemático de aciertos, y el cambio de la educación por el entrenamiento (67). Por más que se retenga el nombre propio del alumno, sin llegar a convertirlo en número, son sus conocimientos los reificados en un sistema pautado y reglado de respuestas válidas, frente a las demás, que devienen inválidas e inservibles; una dinámica que Zambra también pone en crisis cuando incluye algunos planteamientos cuya ruptura discursiva - sobre el discurso del examen - no serían muy ajenos a la subversión de la lógica de un poema (17).

Por este motivo, y dejando de lado las plausibles lecturas foucaultianas o derrideanas que puede propiciar este proceso deconstructivo de Zambra, que devela las oscuras normas de una biopolítica educativa de constricciones seriadas, preferimos asociar su trabajo al de aquellos otros lenguajes que se preguntan, adánicamente, sobre sí mismos y sobre sus elementos compositivos, para lo cual quizá sea más feraz comparar Facsímil y su trabajo reconstructor o deconstructor de la palabra, la frase y el discurso con el que hizo Dziga Vertov en 1929, cuando en Un hombre y su cámara nos presenta también al mismo tiempo la realidad política soviética y las partículas elementales, compositivas, con los que está construido el filme: los fotogramas. El libro de Zambra parece a medio escribir, parece no escrito, pero en realidad no debemos verlo así: está mostrando un proceso, está haciendo lo mismo que Vertov cuando muestra la mesa de montaje de la propia película, lo que luego repetirá Orson Welles en $F$ for Fake (1973), entre otros cineastas. Vertov se propone hacer cine con elementos puramente cinematográficos y abandonar - dice textualmente en los créditos del comienzo - la palabra tomada del teatro y la literatura, para sumergirse en un cine puro, internacional. La misma operación, en manos de Zambra, se vuelve extraña y agudamente nacional, metachilena, como una forma de pensar un país, Chile, mediante el uso educativo de sus palabras. Del mismo modo que la fotocomposición a 24 fotogramas por segundo nos procura una ilusión de realidad, el hecho de responder, como si nos estuviéramos examinando, a las preguntas y cuestionarios de Facsímil, también nos lleva a un modo de mirar la realidad, que más que metaliterario podríamos calificar, en puridad, de metalingüístico. Nos conduce a ser conscientes de cómo se construyen las palabras que nos construyen o que nos destruyen para siempre.

\section{Un ejemplo concreto de utilización narrativa de las cosas tras el fallecimiento: Carlos Busqued}

Arthur Schopenhauer, en un lugar en principio tan poco imaginable como el "Ensayo sobre las visiones de fantasmas" (dentro de Parerga und Paralipomena, 1851), nos dice que las cosas desempeñan un papel inequívoco de nexus idearum. Las 
cosas, a su juicio, hacen de vínculo entre personas, pero también entre conceptos e ideas, y ello nos permite visualizar fenómenos intangibles. Sobre fenómenos intangibles y fantasmáticos se explaya el pensador en ese sugestivo texto, raro en un libro de filosofía, donde podemos encontrar razonamientos sobre los bienes de los muertos (113). Aunque el tema de las cosas supervivientes del difunto parece ser más propio del campo poético, tiene también hueco en la narrativa, y dentro de la prosa hispánica hemos encontrado un caso específico de gran interés: en la excelente y desoladora novela del argentino Carlos Busqued, Bajo este sol tremen$d o$ (2009), el hilo conductor del relato y, al mismo tiempo, las únicas pistas sobre la psique profunda de los personajes vienen conformados por la descripción de sus objetos y la formación de sus colecciones. El protagonista, Cetarti, debe viajar a Lapachito, un pueblo del interior argentino, para hacerse cargo de los cuerpos y las pertenencias post mortem de su madre y de su hermano. Un poco antes de efectuar los breves recuentos de objetos remanentes en sus casas y bolsillos, Cetarti traba contacto con el albacea, Duarte (siendo el albacea el custodio por excelencia de los objetos restantes), de cuya inquietante crueldad elabora un retrato perfecto con tan solo transcribir los títulos de su videoteca, que está vertiendo de cintas VHS a digital para salvarlos del cambio de formato. El archivo, que para Boris Groys implicaba la conservación paulatina de la cultura que importa (55-56), se vuelve en manos de Busqued irónico y corrosivo: Duarte no salva en esas cintas películas de Dreyer o Tarkovski, sino pornografía extrema y actos de sadomasoquismo brutal, y da la siguiente explicación: "hay cierta manera de hacer las cosas que se va perdiendo y cuesta encontrar[...] Está todo cada vez, no sé cómo decirte, más limpio, más profesional. Y eso atenta contra cierta otra cosa por la que uno mira el porno [...] más como por una curiosidad de hasta dónde puede llegar la especie humana" (43), lo que no deja de ser irónico teniendo en cuenta que el propio Duarte se dedica a secuestrar y violar a mujeres y niños con retraso mental. El retrato del hermano muerto de Certati también se hace a través de su colección de objetos; en este caso, bajo la descripción de su piso, fruto de la acumulación desordenada de miles de cosas que apuntarían a un posible trastorno de síndrome de Diógenes (65 y ss.). La recopilación furibunda del hermano se revela como una colección de colecciones, pues en cierto momento Cetarti descubre que "otros dos cajones estaban vacíos y en el último había una variopinta colección de cadáveres de insectos resecos. Colección porque eran muchos como para haber ido a parar ahí por casualidad y porque luego de un breve análisis advirtió que no había muchos especímenes repetidos" (68). De todas las cosas del apartamento de su hermano, Cetarti solo se lleva el objeto que tiene en común con el finado: la pecera (69), mayor que la que él tiene en su propia casa. El retrato psicológico 
de Cetarti puede hacerse también a través de los objetos que abandona, como cuando "olvida" freudianamente "las cenizas de su madre y su hermano" (70) en el maletero del automóvil que ha vendido. Cetarti se muda a la casa de su hermano muerto y comienza a ordenar sus cosas, sacando casi medio centenar de bolsas de basura. Una vez discriminadas las cosas que puede revender, piensa lo siguiente: "se había parado frente al amontonamiento de objetos [...] mirándolo durante un rato largo, como si el conjunto formara un mensaje cifrado que de pronto pudiese cobrar sentido ante sus ojos como reconocimiento a su esfuerzo" (140).

El despojamiento del texto de Busqued, paralelo a la frialdad de los personajes, se anima un poco cuando los objetos cobran simbolismo, al desreificarlos y al cubrirlos de propiedades referenciales. En ese sentido, sería interesante hacer un paralelo entre el uso que Busqued otorga a las peceras que aparecen en el libro (el trasunto de una televisión animada que los personajes ven para no pensar, para no pensarse) y el que le da Mario Bellatin al mismo objeto en Salón de belleza (1994), donde los acuarios se devienen correspondencia de la lenta podredumbre corporal de los personajes. Distintas en su uso, las peceras de Busqued y Bellatin tienen, sin embargo, algo en común: las de Busqued apuntan a enfermedades psíquicas de indiferencia o acedía espiritual como modo de estar en el mundo; mientras que las peceras de Bellatin remiten a una enfermedad física concreta.

\section{Desfamiliarización}

Desfamiliarizar los objetos cotidianos y devolverlos extrañados es algo habitual en las narrativas de César Aira y de Mario Bellatin, para quienes la subversión de los códigos habituales - en los discursos, en los objetos o en los discursos sobre los objetos- es pauta en sus recursos de extrañeza. Puede leerse en Las curas milagrosas del doctor Aira:

Cosas. Cosas tangibles que pudieran tomarse en las manos, guardarse en un cajón. El mundo siempre estaba elogiando a la 'gente joven que hace cosas', y con razón. Porque el noventa y nueve por ciento del valor de las cosas, de su belleza intrínseca, lo pone el tiempo. Un peine solo sirve para peinarse [...], pero un peine de hace doscientos años se vende como un objeto precioso en una casa de antigüedades, y un peine de hace dos mil años se exhibe en un museo y no tiene precio. Por eso en la juventud vale la pena hacer cosas, porque esas cosas son las únicas hechas por nosotros que tenemos la posibilidad, si llegamos a viejos, de alcanzar a ver embellecidas por la pátina del tiempo. Las que se hacen después quedan para las generaciones futuras, y uno se las pierde. (32) 
El fragmento cobra significación no solo per se, sino porque pertenece a un modo de mirar de Aira que se extiende a lo largo de su trayectoria narrativa. Prueba de ello es que en Artforum (2014), el narrador se pregunta si " ${ }_{\mathrm{C}}$ Un objeto podía amar a un hombre?", y describe a los libros y revistas como "superobjetos", pues realizan "doblemente su condición de objetos al ser portadores especializados de información" (13), para lanzarse después a describir un ejemplar de la revista Artforum de forma desfamiliarizada por completo.

Un modo de desfamiliarizar los objetos puede ser alterando la óptica de observación. Un ejemplo ya visto sería realizar el examen de los objetos desde su composición atómica, observándolos con microscopio. Otro modo podría ser graduar de nuevo el ángulo de comprensión de aquellas realidades a las que nos referimos con el nombre de objetos. Por lo común, llamamos cosas u objetos a elementos de pequeño tamaño, pero este poema de la cubana Legna Rodríguez Iglesias nos revela inopinadamente que, en realidad, nuestra mirada es parcial y fallida, pues también hay objetos tan grandes que no los vemos y, en consecuencia, no los consideramos tales: "Allí donde creemos que no hay físicamente nada / resulta que se encuentran los objetos / más pesados / objetos cilíndricos / rectangulares / planos / oblongos / poliédricos / altos y largos / objetos profundos y diversos" (18). En tales supuestos desaparece la escala y la realidad queda retratada como un conjunto de cosas de desigual tamaño, pero de plena continuidad ontológica. Legna Rodríguez Iglesias también entiende, como Spinoza (Etica, III, proposición VI), que las cosas perseveran en su ser ("la cama continúa siendo cama / y el libro continúa siendo libro" [39]), hasta que derivan en símbolo: "pensé: la cama es un símbolo / yo misma soy una cama demasiado alucinante" (39).

\section{Conclusiones}

En esta panorámica hemos dejado fuera algunos temas que hubieran llevado el estudio a una extensión desmesurada: el fetichismo objetual, el desasosiego baudeleriano ante las cosas, del que habla Agamben en Estancias (tampoco abordamos el asunto de las correspondencias entre las cosas del poeta francés, que sería una forma de simbolizar no las cosas, sino las conexiones entre ellas); tampoco abordamos el ágalma lacaniano, ni las cosas mágicas, rituales, invisibles o inmateriales, etcétera. Pero creemos que al ceñirnos a las cosas materiales, observadas desde una perspectiva más o menos natural o normal (que excluye la mirada fetichista), hemos creado algo parecido a un suelo o sustrato de observación plausible.

Dentro de esas coordenadas, hemos colegido que los objetos auráticos nos miran (o nos llaman, como decía Millás en su libro homónimo), mientras que miramos los objetos proyectados, caracterizados por su condición de comple- 
mento directo (objeto directo, se decía en las gramáticas antiguas). En cualquier caso, ambos tipos de cosas comparten nuestra captura perceptual, el hecho de ser mirados de alguna forma: "La verdad de los objetos es precisamente la superficie que presentan al ser capturados", condensa Susan Buck-Morss (154). Hay un diálogo perceptivo entre las cosas y nosotros, sobre todo entre las cosas y la mirada de la literatura: en ese loop o ciclo perceptivo retroalimentado suceden buena parte de los discursos sobre las cosas que hemos visto. En los demás, las cosas son dotadas por el discurso literario de distintas cualidades, mediante la proyección de una mirada personalizadora, mitificante, simbólica, anticlimática o reveladora, que a veces las altera. Cada una de ellas tiene sus propias características específicas, pero todas muestran la importancia que para los autores tienen las cosas como tema narrativo y poético, y en numerosos casos se convierten en médiums entre los objetos y los sujetos, con lo que permiten - sea mediante la asociación, la transmisión, la reificación o la personalización - un diálogo constante entre ambas realidades fenoménicas, si bien bajo una visión concreta, la que hemos denominado ontología científica de las cosas, sujetos y objetos están compuestos de las mismas partículas elementales.

Creo que este panorama que hemos descrito, en especial esa ontología científica detectada en la poesía reciente en castellano, desmonta el pesimista aserto de Philip Silver de que "desde el periodo romántico hasta hoy, la poesía ha sido la repetición de los infructuosos esfuerzos por fundar objetos en un sentido ontológico" (24); constituye un auténtico modo de indagar en lo real mediante el discurso poético (y el narrativo), y levanta construcciones que no intentan postularse como supremacía de los entes, sino como afinación definitoria en nuestro acercamiento, cada vez más preciso, a lo que nos rodea y a lo que somos.

\section{Obras citadas}

Aguado, Jesús. Heridas. Sevilla: Renacimiento, 2004. Impreso.

Aguilar Bautista, Virginia. Seguir un buzón. Sevilla: Renacimiento, 2010. Impreso.

Aira, César. Artforum. Buenos Aires: Blatt \& Ríos, 2014. Impreso.

Aira, César. Las curas milagrosas del doctor Aira. México D. F.: Era, 2003. Impreso.

Darío, Rubén. Obras selectas. Madrid: Edimat, 2001. Impreso.

Borges, Jorge Luis. Obras completas. Vol. II. Buenos Aires: Emecé, 1989. Impreso.

Brea, José Luis. Nuevas estrategias alegóricas. Tecnos, 1991. Impreso.

Buck-Morss, Susan. "Estudios visuales e imaginación imaginación global".

Estudios visuales: la epistemología de la visualidad en la era de la globalización. Ed. José Luis Brea. Madrid: Akal, 2005. 145-159. Impreso.

Busqued, Carlos. Bajo este sol tan tremendo. Barcelona: Anagrama, 2009. Impreso. 
Cabezón Cámara, Gabriela. La virgen cabeza. Buenos

Aires: Eterna Cadencia, 2009. Impreso.

Chéjov, Antón Pávlovich. Cuentos. Valencia: Pre-Textos, 2008. Impreso.

Clariond, Jeanette L. Todo antes de la noche. Valencia: Pre-Textos, 2003. Impreso.

Crespo, Ángel. En el medio del camino: poesía, 1949-

1970. Barcelona: Seix Barral, 1971. Impreso.

Davenport, Guy. Objetos sobre una mesa: desorden armonioso en arte y literatura.

Madrid: Turner/Fondo de Cultura Económica, 2002. Impreso.

Dennet, Daniel C. Tipos de mentes: hacia una comprensión de

la conciencia. Madrid: Debate, 200o. Impreso.

Didi-Huberman, Georges. Lo que vemos, lo que nos mira.

Manantial: Buenos Aires, 2011. Impreso.

Dobry, Edgardo. Cinética. Dilema, 2004. Impreso.

Eagleton, Terry. El acontecimiento de la literatura. Barcelona: Península, 2013. Impreso.

Fernández Mallo, Agustín. Nocilla Dream. Canet de Mar: Candaya, 2006. Impreso.

Francalanci, Ernesto L. Estética de los objetos. Madrid:

Antonio Machado Libros, 2010. Impreso.

Fresán, Rodrigo. La parte inventada. Barcelona: Random House, 2014. Impreso.

Gadamer Hans-George. Mito y razón. Barcelona: Paidós, 1999. Impreso.

Galindo, Bruno. El público. Madrid: Lengua de Trapo, 2011. Impreso.

Gandolfo, Elvio E., comp. Un silencio menos. Buenos Aires: Mansalva, 2013. Impreso.

García Maffla, Jaime. ¿Qué es la poesía? Bogotá: Editorial

Pontificia Universidad Javeriana, 2001. Impreso.

González Sainz, J. Á. El viento en las hojas. Barcelona: Anagrama, 2014. Impreso.

Gopegui, Belén. El comité de la noche. Barcelona: Random House, 2014. Impreso.

Groys, Boris. Sobre lo nuevo. Valencia: Pre-Textos, 2005. Impreso.

Hernando, Almudena. La fantasía de la individualidad: sobre la construcción

sociohistórica del sujeto moderno. Madrid: Katz, 2012. Impreso.

Houellebecq, Michel. Les particules élémentaires. Paris: Flammarion, 1998. Impreso.

Ibáñez, Andrés. Brilla, mar del Edén. Barcelona: Galaxia Gutemberg, 2014. Impreso.

Jiménez, Juan Ramón. Antología poética de fuan Ramón

Fiménez. Madrid: Biblioteca Nueva, 1981. Impreso.

Lledó, Emilio. El silencio de la escritura. Madrid: Espasa Calpe, 1998. Impreso.

Maqueira, Ezio. "Autólisis"- Panorama interzona. Comp. Elsa Drucaroff.

Buenos Aires: Interzona Editora, 2012. 116-117. Impreso.

Martel, Frédéric. Smart. Internet(s): la investigación. Madrid: Taurus, 2014. Impreso.

Moga, Eduardo. Insumisión. Madrid: Vaso Roto, 2013. Impreso. 
Mora, Vicente Luis. La literatura egódica. Valladolid:

Universidad de Valladolid, 2013. Impreso.

Mora, Vicente Luis. La luz nueva. Córdoba: Berenice, 2007. Impreso.

Mora, Vicente Luis. Pasadizos: espacios simbólicos entre arte y

literatura. Madrid: Páginas de Espuma, 2008. Impreso.

Moreno, Javier. La imagen y su semejanza. Santa Coloma de Gramenet: La Garúa, 2015. Impreso.

Neruda, Pablo. Obras escogidas. Santiago de Chile: Andrés Bello, 1972. Impreso.

Norman, Donald. La psicología de los objetos cotidianos. Madrid: Nerea, 199o. Impreso.

Pérez Galdós, Benito. Marianela. Madrid: Alianza, 2011. Impreso.

Ramírez, Juan Antonio. El objeto y el aura: (des)orden visual del arte moderno. Madrid: Akal, 2009. Impreso.

Rodríguez Iglesias, Legna. Chupar la piedra. La Habana:

Casa Editora Abril, 2013. Impreso.

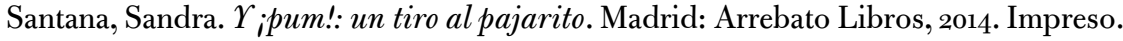

Sartre, Jean Paul. La náusea. Madrid: Unidad, 1999. Impreso.

Schopenhauer, Arthur. Ensayo sobre las visiones de

fantasmas. Madrid: Valdemar, 1997. Impreso.

Silver, Philip W. La casa de Anteo: ensayos de poética hispana. Madrid: Taurus, 1985. Impreso.

Stevens, Wallace. Harmonium. Barcelona: Icaria, 2002. Impreso.

Szymborska, Wyslava. El gran número: fin y principio y otros poemas.

Trad. Carlos Marrodán Casas. Madrid: Hiperión, 2007. Impreso.

Tizón, Eloy. Seda salvaje. Barcelona: Anagrama, 1995. Impreso.

Trejos, Alfredo. Prefiero ver estática. San José: Germinal, 2013. Impreso.

Valéry, Paul. Cuadernos (1894-1945). Ed. Andrés Sánchez Robayna.

Barcelona: Galaxia Gutenberg, 2007. Impreso.

Valladares, Sheyla. "La oscuridad". Web. 31 de julio de 2014.

Vallejo, César. The Complete Posthumous Poetry. Ed. Clayton Eshleman.

Oakland: University of California Press, 1978. Impreso.

Zambra, Alejandro. Facsímil. Madrid: Sexto Piso, 2015. Impreso.

Zambra, Alejandro. Mis documentos. Barcelona: Anagrama, 2014. Impreso.

Zambrano, María. Filosofía y poesía. México D. F.: Fondo de Cultura Económica, 1993. Impreso.

Zizek, Slavoj. Visión de paralaje. Buenos Aires: Fondo de Cultura Económica, 2006. Impreso. 